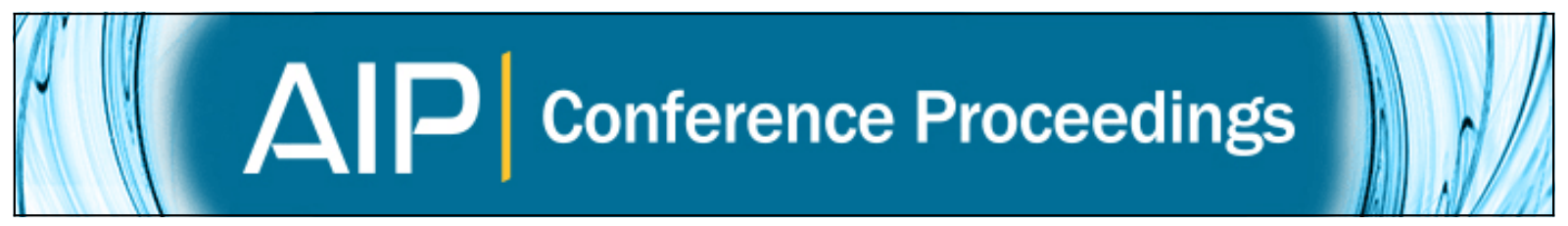

\title{
A new approach to wind energy: Opportunities and challenges
}

John O. Dabiri, Julia R. Greer, Jeffrey R. Koseff, Parviz Moin, and Jifeng Peng

Citation: AIP Conference Proceedings 1652, 51 (2015); doi: 10.1063/1.4916168

View online: http://dx.doi.org/10.1063/1.4916168

View Table of Contents: http://scitation.aip.org/content/aip/proceeding/aipcp/1652?ver=pdfcov

Published by the AIP Publishing

\section{Articles you may be interested in}

New opportunities and challenges for women in physics in China

AIP Conf. Proc. 1517, 88 (2013); 10.1063/1.4794233

Smart textiles: Challenges and opportunities

J. Appl. Phys. 112, 091301 (2012); 10.1063/1.4742728

A Distributed Approach to Computational Earthquake Science: Opportunities and Challenges

Comput. Sci. Eng. 14, 31 (2012); 10.1109/MCSE.2012.59

Neutrino Detectors: Challenges and Opportunities

AIP Conf. Proc. 1382, 42 (2011); 10.1063/1.3644267

Future Directions, Challenges and Opportunities in Nuclear Energy

AIP Conf. Proc. 894, 32 (2007); 10.1063/1.2717951 


\title{
A New Approach To Wind Energy: Opportunities And Challenges
}

\author{
John O. Dabiria, Julia R. Greera , Jeffrey R. Koseff ${ }^{b}$, Parviz Moinc ${ }^{c}$, and Jifeng Peng ${ }^{\mathrm{d}}$ \\ ${ }^{a}$ Division of Engineering and Applied Science, California Institute of Technology, Pasadena, CA 91125, USA \\ ${ }^{b}$ Department of Civil and Environmental Engineering, Stanford University, Stanford, CA 94305, USA \\ ${ }^{c}$ Center for Turbulence Research, Stanford University, Stanford, CA 94305, USA \\ ${ }^{d}$ Department of Mechanical Engineering, University of Alaska Anchorage, Anchorage, AK 99508, USA
}

\begin{abstract}
Despite common characterizations of modern wind energy technology as mature, there remains a persistent disconnect between the vast global wind energy resource - which is 20 times greater than total global power consumption - and the limited penetration of existing wind energy technologies as a means for electricity generation worldwide. We describe an approach to wind energy harvesting that has the potential to resolve this disconnect by geographically distributing wind power generators in a manner that more closely mirrors the physical resource itself. To this end, technology development is focused on large arrays of small wind turbines that can harvest wind energy at low altitudes by using new concepts of biology-inspired engineering. This approach dramatically extends the reach of wind energy, as smaller wind turbines can be installed in many places that larger systems cannot, especially in built environments. Moreover, they have lower visual, acoustic, and radar signatures, and they may pose significantly less risk to birds and bats. These features can be leveraged to attain cultural acceptance and rapid adoption of this new technology, thereby enabling significantly faster achievement of state and national renewable energy targets than with existing technology alone. Favorable economics stem from an orders-of-magnitude reduction in the number of components in a new generation of simple, mass-manufacturable (even 3D-printable), vertical-axis wind turbines. However, this vision can only be achieved by overcoming significant scientific challenges that have limited progress over the past three decades. The following essay summarizes our approach as well as the opportunities and challenges associated with it, with the aim of motivating a concerted effort in basic and applied research in this area.
\end{abstract}

Keywords: wind energy, wind farms, renewable energy, vertical-axis wind turbines

PACS: 88,47

\section{BACKGROUND AND MOTIVATION}

Comparisons between renewable energy and conventional fossil fuels can be made from a variety of perspectives, including carbon emissions, water use, operations and maintenance, and of course, cost. A common starting point is the observation that the sources of renewable energy - primarily solar radiation and wind - are more diffuse than coal, oil, and natural gas. Indeed, whereas a typical coal powerplant will produce 90 watts of power per square meter $\left(\mathrm{W} / \mathrm{m}^{2}\right)$ of the powerplant footprint, concentrating solar powerplants generate approximately $20 \mathrm{~W} / \mathrm{m}^{2}$, and modern wind farms average $2-5 \mathrm{~W} / \mathrm{m}^{2}[1,2]$. However, these numbers obscure a unique and potentially transformative advantage of renewable energy, namely its global availability. For example, Figure 1 compares the

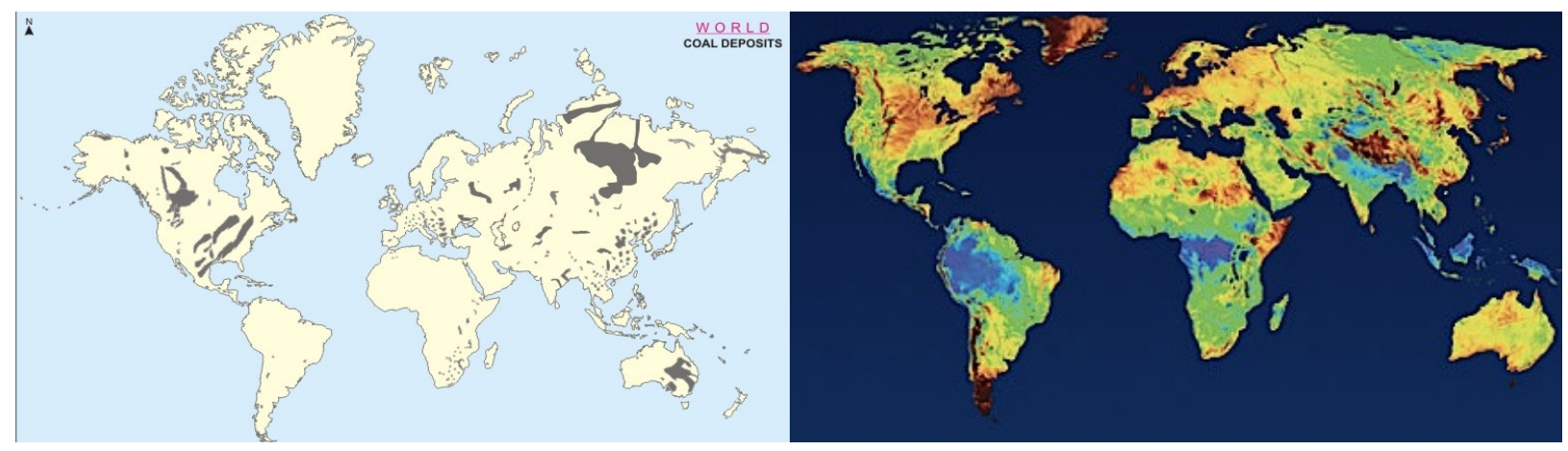

FIGURE 1. Left, World coal deposits (grey) [6]. Right, World wind speeds at $80 \mathrm{~m}$ over land [7] Copyright (c) 2011 3TIER, Inc. (Readers of print version (gray image) can find color coding-blue (e.g. Amazonia, Central Africa) to red (e.g. central N. America) -3 to $9 \mathrm{~m} / \mathrm{s}$ at [24]). 
geographic distribution of coal reserves with the geographic distribution of wind around the world. Coal, like other fossil fuels, is a highly localized source of energy, found underneath less than 5 percent of the world's land area [3, 4]. Wind, by contrast, is ubiquitous. With the exception of heavily forested areas of the Amazon, Congo, and southeast Asia, wind is available for conversion to useful energy in nearly every corner of the globe. Moreover, these wind resources are enormous - the estimated 250 trillion watts of global wind power is 20 times greater than total global power consumption - and they appear in settings as diverse as arid desert and the urban canyons of major metropolitan cities [5].

Despite the global availability of wind resources, wind energy technology has thus far had only a modest impact on power generation worldwide. Only 4 countries currently generate more than 10 percent of their electricity from wind, all of them in Europe. There are local instances of high wind energy penetration in the U.S. in states such as Iowa and South Dakota; nonetheless, only 4 percent of electricity generated in the U.S. is derived from the wind [8]. Perhaps most poignant is the example of developing countries such as Somalia and Malawi, which have excellent wind resources and yet still suffer some of the lowest household electrification rates in the world $[9,10]$.

To what can we ascribe this dichotomy between the abundance of wind energy resources and the limited adoption of existing wind energy technologies? Many economic, infrastructural, regulatory, and cultural issues contribute. However, a root cause is the extant paradigm of wind energy generation, one that relies on power generation by a few, increasingly large wind conversion machines. This centralized approach to power generation arose following the Industrial Revolution as a consequence of the need to process highly localized fossil fuel sources [11]. The trend has been exacerbated by conventional propeller-style wind turbines (i.e., horizontal-axis wind turbines or HAWTs), which must be spaced far apart in order to avoid aerodynamic interference and fatigue loading caused by interactions with the wakes of adjacent turbines (Fig. 2). This requirement has forced wind energy systems away from high energy demand population centers and toward remote locations including, more recently, offshore sites. It has also necessitated the implementation of very large wind turbines, so that the inefficiency of the wind farm as a whole can be mitigated by accessing the greater wind resources available at high altitudes. However, by limiting ourselves to this approach in the harvesting of wind energy, we have forfeited key advantages and opportunities afforded by a globally distributed energy source like the wind:

- the ability to generate energy close to its point of consumption;

- the functional versatility inherent in energy conversion devices that can scale from kilowatts to megawatts;

- access in rural communities and the developing world, where local electricity generation can be especially valuable in the absence of a reliable centralized power grid; and

- $\quad$ potentially lower barriers to adoption of distributed wind energy technologies versus the status quo.

To be sure, economies of scale have been demonstrated to favor larger wind turbine components. We hypothesize that this constraint can be circumvented in part by simplifying the underlying wind turbine design, reducing the

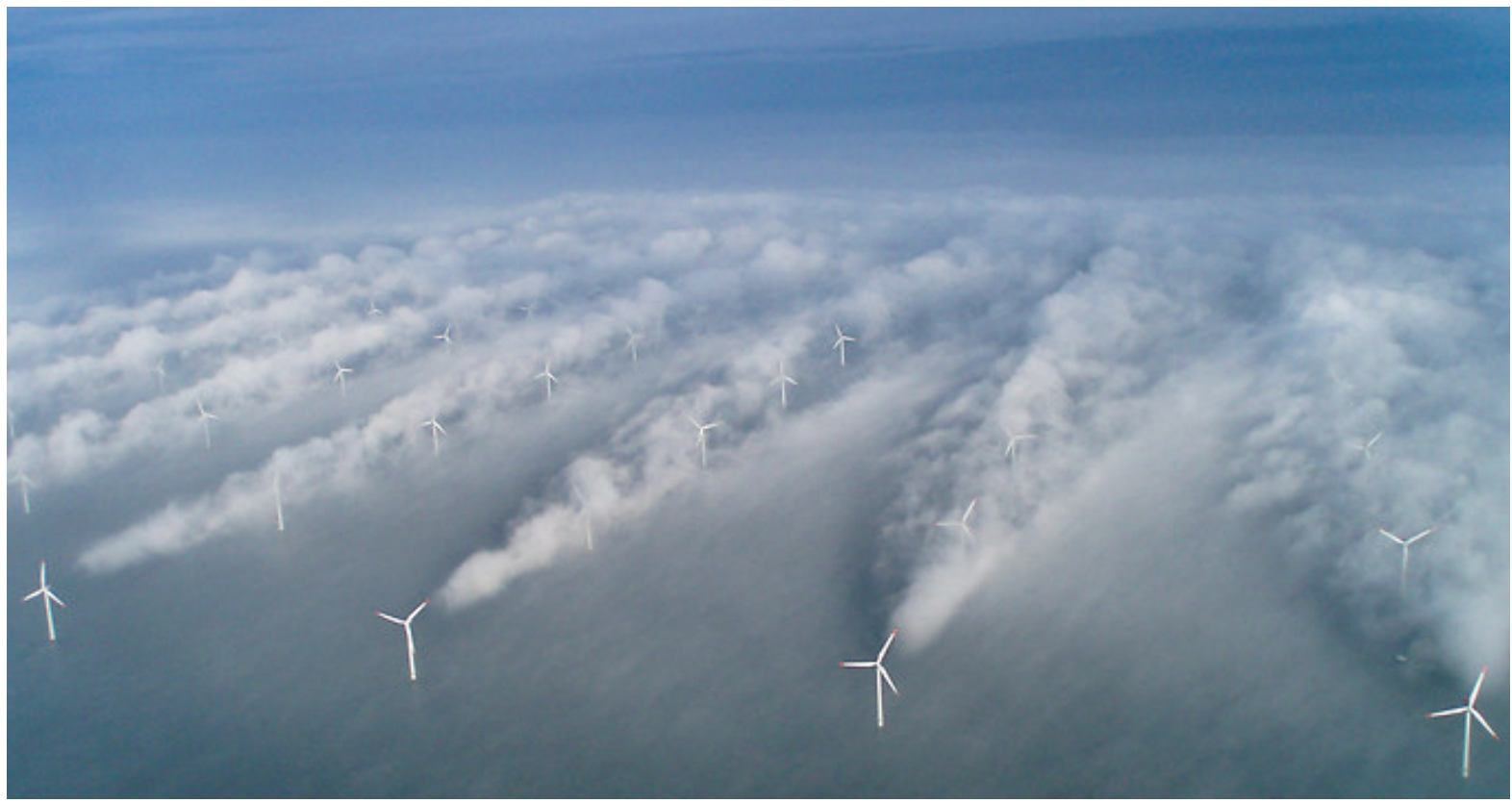

FIGURE 2. Horns Rev Offshore Wind Farm, North Sea. Turbulent wakes visible in fog behind front row of turbines. Photo Credit: Christian Steiness. 


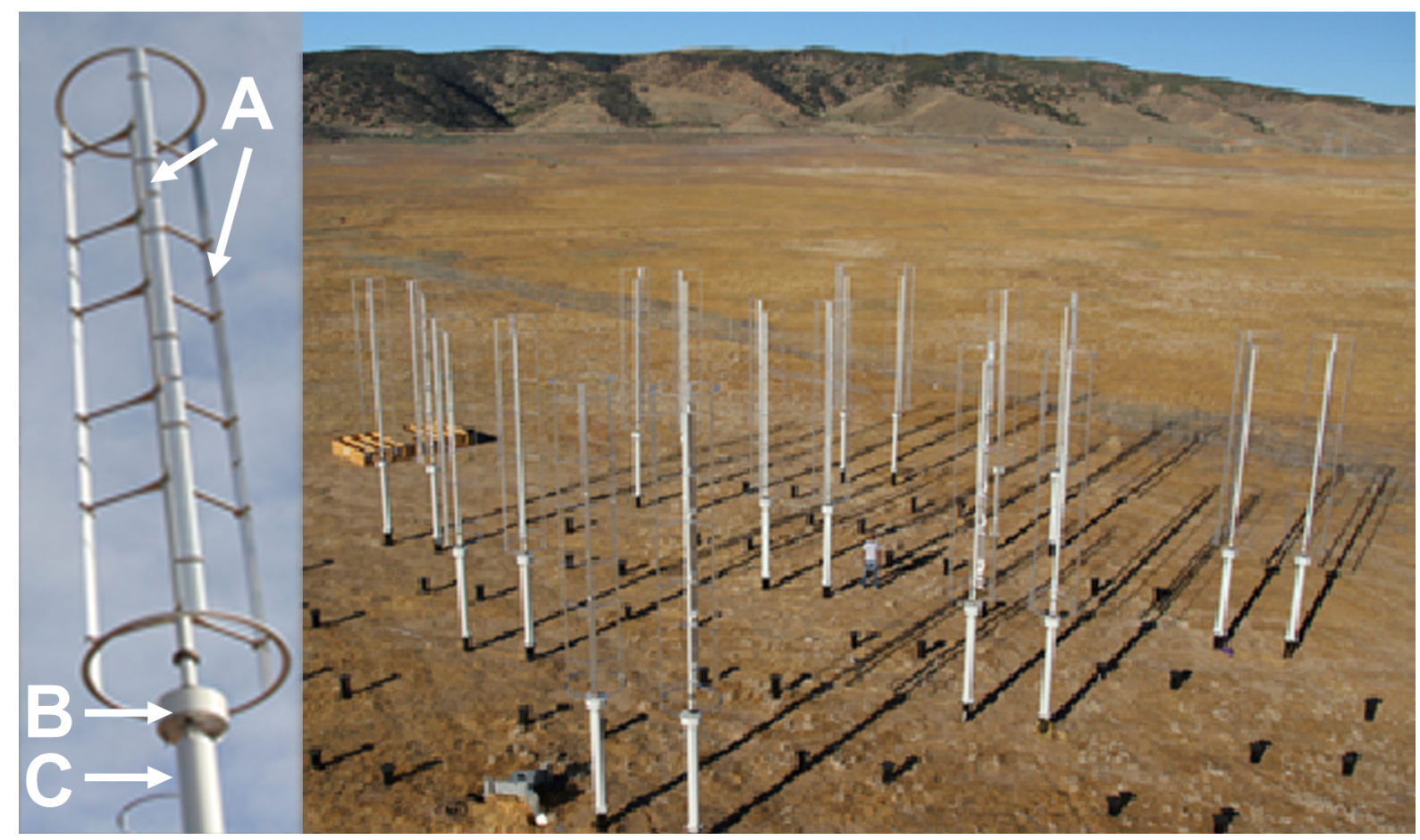

FIGURE 3. Left, Commercially-available VAWT. Vertically-oriented blades (A) with airfoil cross-sections rotate around the vertical axis of the turbine, turning an electrical generator (B) mounted on the tower (C). Right, Caltech Field Laboratory for Optimized Wind Energy (FLOWE). Arrays of up to 24 commercially-available VAWTs are tested in various configurations to study aerodynamic interactions and power generation. Scale is indicated by person standing in center of array. Video is available at http://www.youtube.com/watch?v=cZu-4Plk_5A.

number of components in each wind turbine from approximately 8000 in a modern HAWT to fewer than a dozen in the next generation of small, vertical-axis wind turbines (VAWTs; Fig. 3). Some components such as the gearbox are indeed more cost-effective in large systems; however, they are eliminated altogether in the VAWTs. The vertical-axis design obviates the need for a mechanism to orient the wind turbine toward the oncoming wind, thereby eliminating another cost factor. And, the smaller wind turbine size facilitates the use of low-cost structural components, such as wood towers that cost up to 90 percent less than equivalent steel towers. Together, these savings can more than

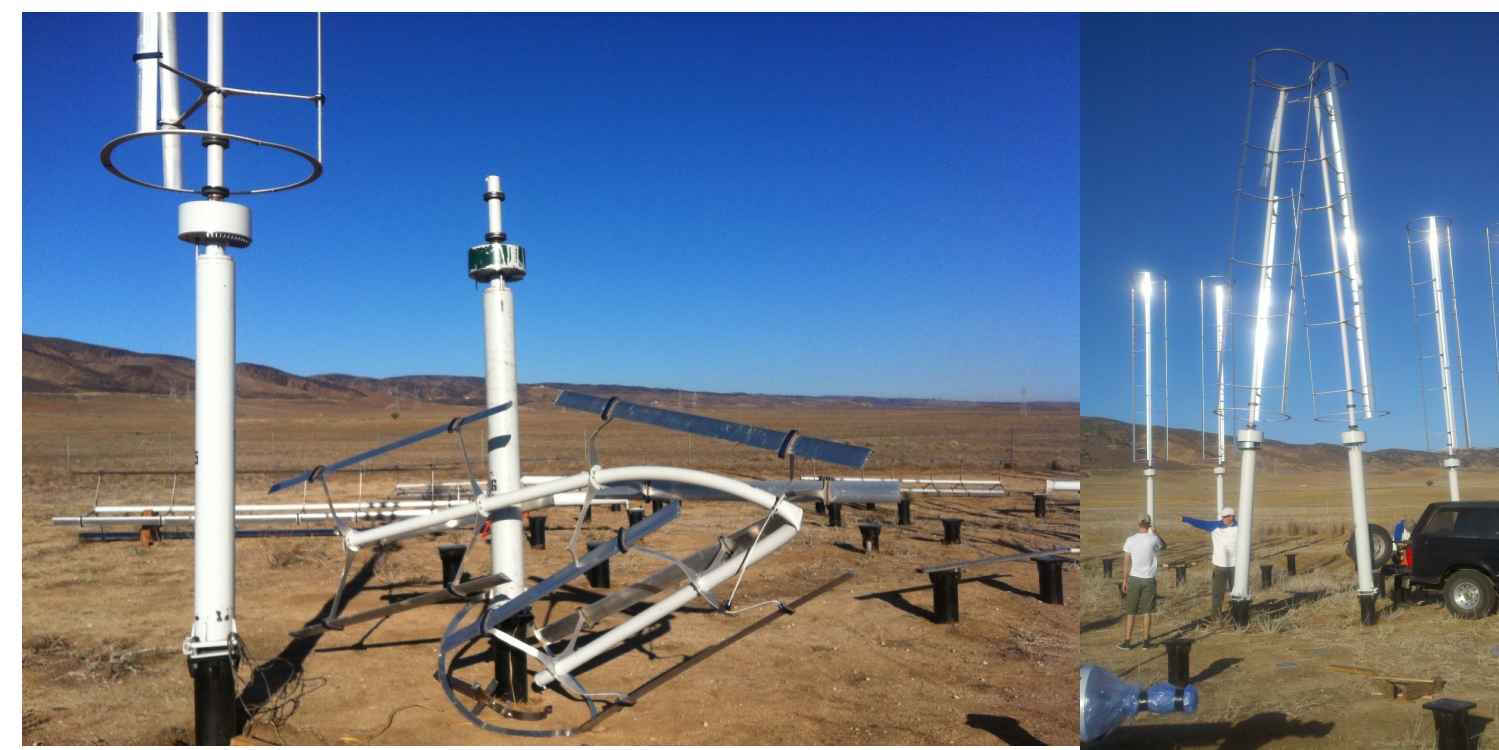

FIGURE 4. Examples of VAWT structural failures at the Caltech Field Laboratory for Optimized Wind Energy (FLOWE). 


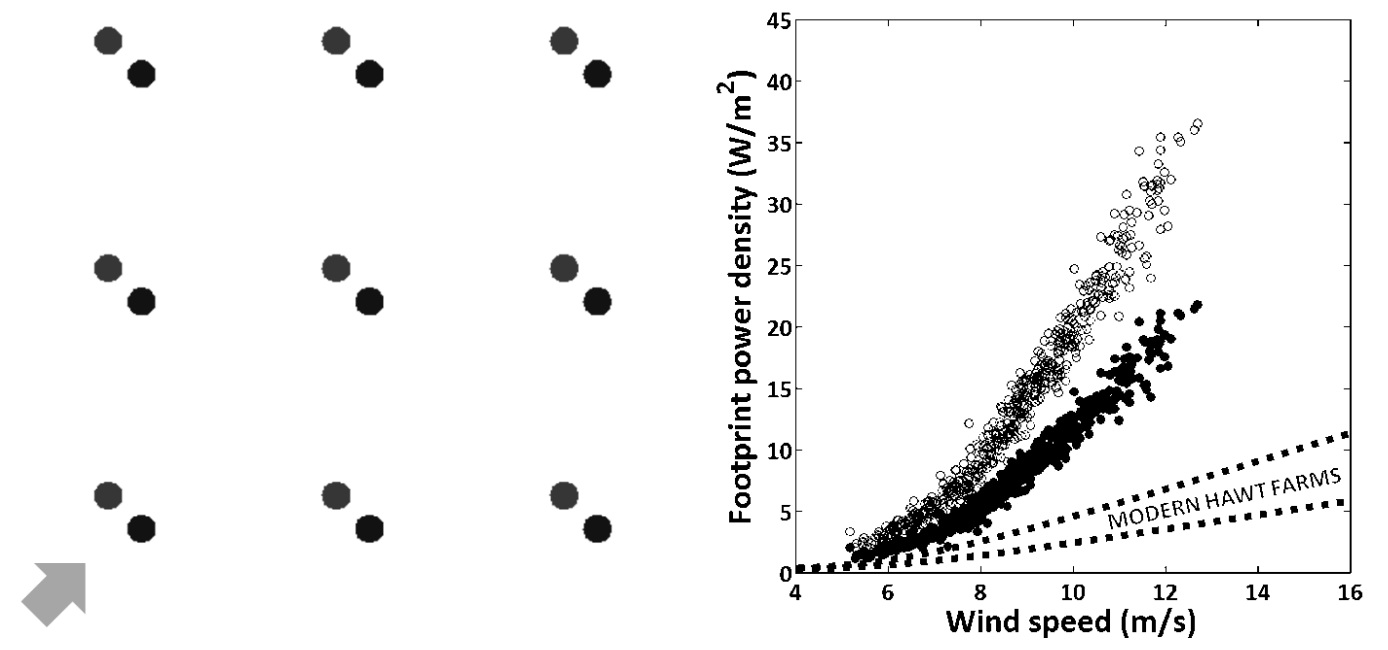

FIGURE 5. Left, Top view of 18-VAWT array configuration. Grey arrow indicates prevailing wind direction. VAWT diameter and spacing is drawn to scale. VAWT pairs are counter-rotating with the direction of blade motion between turbine pairs either upwind or downwind for all 9 pairs in each test. Right, Measurements of footprint power density for 18-VAWT arrays at FLOWE. Open circles, direct measurements. Filled circles, extrapolation of direct measurements to an infinite array of VAWTs using a geometric correction factor. Each data point represents one ten-minute average measurement in the field. Dashed range indicates modern HAWT farm performance (adapted from [2]).

offset the disadvantage of operating at lower altitudes where wind speeds can be lower. Moreover, at 89 percent of wind stations worldwide, the wind class rating does not decrease when altitude is reduced from $80 \mathrm{~m}$ to $10 \mathrm{~m}$ [12].

It is natural to ask why this approach has not been pursued previously. Research on VAWTs in the 1980s demonstrated that their aerodynamics are more complex than HAWTs, thereby making their response to fatigue loading less predictable. Following notable structural failures in the field, the VAWT concept was largely abandoned [13]. Our field tests and other experience nationwide have shown that, even today, the best commercially available VAWTs suffer structural and/or electrical failure within months if not weeks of initial commissioning [14; see also Fig. 4]. Nonetheless, the problem of reliable VAWT design is ripe for solution if recent advances in computational fluid dynamics, materials science, electrical engineering, and experimental diagnostics can be harnessed in a coherent, multidisciplinary research program.

Although field testing over the past four years at the Caltech Field Laboratory for Optimized Wind Energy (FLOWE) has revealed the limitations of existing small-scale VAWT technology, it has also confirmed that wind energy can be harvested effectively at low altitudes previously assumed impractical due to correspondingly lower wind speeds. To date, over 10,000 hours of measurements have been collected in full-scale field tests of $10-\mathrm{m}$ tall VAWTs configured in various arrangements, including many inspired by principles of fish schooling [15]. The results have demonstrated the potential for factor of 10 increases in wind energy production for a given turbine array footprint compared to modern wind farms, despite using wind turbines that are one-tenth of the height of modern structures and also conservatively spaced in the array. [Fig. 5; 15-17]. This counterintuitive result opens up a diverse portfolio of opportunities to apply this approach for wind energy harvesting. The following three sections describe compelling examples of specific near-term applications that motivate further research in this area.

\section{STRATEGIC OPPORTUNITIES}

\section{Electricity Generation in Remote Alaskan villages}

Alaska ranks second in the nation in per capita energy consumption, third in per capita carbon dioxide emissions, and fourth in electricity prices [4]. The state also lacks a comprehensive interconnected electrical grid such as that found in the lower 48 states; instead, many rural communities rely on diesel fuel that must be transported through harsh environments to produce electricity. Alaska therefore provides a unique opportunity to research the ways in which the present approach to wind energy generation can satisfy energy demand while reducing the cost and carbon footprint of electricity generation. Specifically, a greater penetration of wind energy in the region can reduce the dependence on diesel fuel and associated potential environmental hazards, while augmenting energy security by adding diversity to the energy generation portfolio and lowering the cost of energy. Moreover, field testing in Alaska provides an ideal platform for engaging the extensive community of Native Americans in Alaska's tribal villages, 
where as many as half of the high school students drop out before graduation, fewer than 2 percent graduate from college, and the unemployment rate is the highest among all Native Americans [18, 19]. Workforce development in these communities - in the specific context of renewable energy - has the potential to motivate student retention and achievement with an exciting and immediately relevant curriculum that trains the future leaders of a new, local energy industry. The challenging environmental conditions in Alaska provide a rigorous, real-world test of wind energy technologies that today are often designed primarily in controlled laboratory studies or in silico. Research in this area of the world also has a broader environmental significance, as the Bristol Bay region that comprises many small, energy-dependent villages also contains half of the world's sockeye salmon fisheries [20].

\section{Repowering Technologies for California's Aging Wind Farms}

Global expenditures for the operation and maintenance of wind farms are expected to reach $\$ 13$ billion annually within this decade [21]. Much of this cost is associated with the need to repower aging wind farms, either to increase power production or to satisfy new environmental regulations related to noise production and impacts on migratory birds and bats. Because California was the first state to develop large-scale wind farms, it is also the first to face many of the technical and economic challenges associated with wind farm repowering. The low profile and high power density of the VAWT systems described above gives them the potential to be sited within existing wind farms to augment power production or to replace power generation by older wind turbines. For example, the Altamont Pass in northern California, which was one of the first wind farms in the U.S., currently produces an average of 1 watt of power per square meter of footprint [22]. The measured $10-20 \mathrm{~W} / \mathrm{m}^{2}$ average performance of the VAWT arrays can translate to a more than doubling of the farm's power production by distributing VAWTs in localized favorable wind conditions below the HAWTs.

It remains unknown how co-located VAWTs and HAWTs will interact aerodynamically or how to optimize that interaction. Previous experience in full-scale studies of VAWTs has proven that it is essential to complement labscale experiments and computer models with testing in the field to answer this type of question rigorously. Hence, field experience can create an essential feedback loop in the technology development process. An ideal setting for this type of research is the aforementioned Altamont Pass, which contains the largest concentration of wind turbines in the world [22].

\section{Personalized Energy}

The present focus on smaller, simpler wind energy systems presents a unique opportunity to utilize point-of-use manufacturing technologies such as 3D printing to realize energy systems customized for use by individuals, families, or small communities. This do-it-yourself (DIY) approach leverages the global rise of the Maker Movement [23] to empower interested parties to construct and deploy wind energy conversion devices. A potentially transformative milestone in this endeavor is the achievement of fully 3D-printed, kilowatt-scale VAWT components. The size of the relevant VAWT components, though beyond the current capabilities of most 3D printing systems, could feasibly be accommodated in the next few years as the manufacturing technology matures. Success would enable dramatic reductions in the cost of wind energy systems, a benefit that is unique to small-scale wind turbines compatible with a $3 \mathrm{D}$ printing paradigm.

\section{RESEARCH CHALLENGES}

The potential of these ideas to lead a fundamental change in how we produce and consume electricity will only be realized by systematically and rigorously addressing several longstanding scientific barriers to progress. To this end, we suggest a research plan organized around the following interconnected research thrusts that answer the fundamental questions: Where is useful wind energy located? What can we do to better harvest it? And, how can we optimize the function, integration, and adoption of those systems?

\section{Wind Energy Resource Quantification}

Existing wind resource maps are based on sensors intentionally located far from structures such as buildings and trees, as those objects create more complex wind fields that make it difficult to interpret sensor measurements. However, the distributed wind energy systems that are envisaged here will often be sited in such complex wind fields. Therefore, it is essential to develop a physics-based understanding of the flow-structure interactions that occur in built environments, with particular emphasis on how to reconstruct local wind fields from sensor networks 
located in these complex settings. Research activities in this thrust should include wind and water tunnel measurements and computer simulations of canonical flow-structure interactions; development of new computational tools to assimilate crowdsourced wind data from inexpensive, massively distributed wind sensors; and formal quantification of uncertainty in the resulting wind models. A example outcome of this effort would be holistic, open-source city, state, and national maps of the wind resources that are accessible for power generation from individual to utility-scale use.

\section{Wind Turbine Design for Manufacturability and Reliability}

A complementary research goal is to develop wind turbine design concepts that support the paradigm of distributed deployment and operation. The effort should emphasize design and fabrication of low-cost, lightweight, and damage-tolerant materials using sustainable manufacturing processes (including 3D printing); and development of reliable VAWT systems. Research activities in this thrust could include creation of smart, functionally-graded materials through control of structural architecture and material microstructure; development of new nanofabrication methodologies that support scalable manufacturing; testing of flow control strategies for customized VAWT torque and noise characteristics; design of rotor blades with enhanced tolerance to biofouling and icing; and evaluation of earth-abundant, locally-sourced materials for wind turbine manufacturing in developing regions.

\section{Wind Turbine Array Optimization}

An essential research objective is the optimization of aerodynamic and electrical interactions of wind turbines in an array in order to maximize energy generation, improve the reliability and lifetime of power generation, and minimize cost. Concepts from autonomous and networked systems, bio-inspired engineering, optimal control theory, and computational fluid dynamics can enable dynamic optimization of wind power generation via automatic, realtime feedback control and data sharing among the individual units in an array. A rich parameter space is available to be explored for optimization in the lab and field, including static and dynamic turbine height, spacing, and array configuration; power processing protocols; co-location with HAWTs; hybridization with solar power, diesel fuel, and battery storage; and integration with floating platforms for offshore wind applications.

\section{CONCLUSION}

In this paper, we have briefly outlined a vision for an alternative to the status quo in development of wind energy technology. To be sure, this approach is not mutually exclusive of the current trajectory in the field. Indeed, a significant opportunity may lie in the co-location of conventional HAWTs and VAWTs. There is nonetheless a unique set of opportunities afforded by the present approach to wind harvesting based on large arrays of small, simple VAWTs that can in many cases supplant conventional HAWTs or simply be used in locations and applications that are inaccessible to HAWTs. In either case, there remains significant additional research to be completed to achieve the full, global potential of wind energy suggested here. The roadmap and near-term applications described herein may serve as a useful starting point for that effort.

\section{ACKNOWLEDGEMENTS}

The authors gratefully acknowledge funding from the Gordon and Betty Moore Foundation, the Office of Naval Research, and the National Science Foundation.

\section{REFERENCES}

1. T. Nace "Which has a bigger footprint, a coal plant or a solar farm?" Grist. Grist Magazine, Inc. 18 November 2010 . Web version 29 May 2013. http://grist.org/article/2010-11-17-which-has-bigger-footprint-coal-plant-or-solar-farm/

2. D.J.C. MacKay Sustainable Energy---Without the Hot Air. Cambridge: UIT Cambridge Ltd., 2009.

3. World Energy Council. Survey of Energy Resources 2010. London, UK, 2010.

4. U.S. Energy Information Administration. Web. 29 May 2013. http://www.eia.gov/

5. M.Z. Jacobson and C.L. Archer "Saturation wind power potential and its implications for wind energy." Proceedings of the National Academy of Sciences of the USA 109 (15): 679-684. 2012. 
6. Maps of the World. Web. 29 May 2013. http://www.mapsofworld.com/business/industries/coal- e n e r g y / w o r 1 d - c o a 1 deposits.html. Used by permission of Maps of the World.

7. J. Kanter "Mapping the world for a wind-powered future." Green. The New York Times Company. 5 December 2008. Web. 29 May 2013. http://green.blogs.nytimes.com/2008/12/05/mapping-the-world-for-a-wind-powered-future/

8. U.S. Department of Energy. Electric Power Monthly data for March 2012. Washington, USA, 2012

9. J. Dodd "Malawi looks to wind for energy solution." Wind Power Monthly. Haymarket Media Group Ltd. 26 September 2012. Web. 29 May 2013. http://www.windpowermonthly.com/article/1151953/malawi-looks-wind-energy-solution

10. R. Pallabazzer and A.A. Gabow "Wind resources of Somalia." Solar Energy 46 (5): 313-322. 1991.

11. C. Sulzberger "Thomas Edison's 1882 Pearl Street Generating Station.” IEEE Global History Network. IEEE. 7 September 2010. Web. 29 May 2013. http://www.ieeeghn.org/wiki/images/a/ae/Edison_and_Pearl_Street\%2C_Text\%2C_031410.pdf

12. C.L. Archer and M.Z. Jacobson "Evaluation of global wind power." Journal of Geophysical Research 110: D12110.2005.

13. P. Asmus Reaping the Wind: How Mechanical Wizards, Visionaries, and Profiteers Helped Shape Our Energy Future. Washington, D.C. Island Press, 2001.

14. Associated Press. "Some Nevada wind power users says returns lacking." Fox News. Fox News Network LLC. 27 September 2012. Web. 16 July 2013. http://www.foxnews.com/us/2012/09/27/some-nevada-wind-power-users-say-returns-lacking/

15. R.W. Whittlesey, S.C. Liska, and J.O. Dabiri "Fish schooling as a basis for vertical-axis wind turbine farm design." Bioinspiration and Biomimetics 5: 035005.

16. J.O. Dabiri "Potential order-of-magnitude enhancement of wind farm power density via counter-rotating vertical-axis wind turbine arrays." Journal of Renewable and Sustainable Energy 3: 043104.

17. M. Kinzel, Q. Mulligan, and J.O. Dabiri "Energy exchange in an array of vertical-axis wind turbines," Journal of Turbulence 13: $1-13$

18. Garland, S. "In remote Alaskan villages, teachers struggle to make school meaningful." The Atlantic. The Atlantic Monthly Group. 28 February 2013. Web. 29 May 2013. http://www.theatlantic.com/national/archive/2013/02/in-remote-alaskanvillages-teachers-struggle-to-make-school-meaningful/273596/

19. Alaska Beat. "Native American unemployment rate worst in Alaska." Alaska Dispatch. Alaska Dispatch. 6 January 2011. Web. 4 July 2013. http://www.alaskadispatch.com/article/native-american-unemployment-rate-worst-alaska

20. U.S. Environmental Protection Agency. About Bristol Bay. 11 March 2013. Web. 29 May 2013. h t tp :// w w w 2 . e p a .g o v/ bristolbay/about-bristol-bay

21. Dvorak, P. "The state of O\&M operations thru 2020." Windpower Engineering and Development. WTWH Media LLC. 10 February 2012. Web. 29 May 2013. http://www.windpowerengineering.com/construction/report-the-state-of-om-operationsthru-2020/

22. Lowitz, M. "Altamont Pass, California." The Encyclopedia of Earth. Environmental Information Coalition, National Council for Science and the Environment. 18 August 2011. Web. 29 May 2013. http://www.eoearth.org/article/ Altamont_Pass,_California

23. Anderson, C. "The Maker Movement: Tangible goods emerge from ones and zeros." Wired Magazine. Conde Nast. 16 April 2013. Web. 9 July 2013. http://www.wired.com/magazine/2013/04/makermovement/

24. R. H. Knapp, Barbara G. Levi and Daniel Kammen, eds. Physics of Sustainable Energy III. AIP Conference Proceedings 1652, American Institute of Physics, Melville, NY (2015). Online version at http://scitation.aip.org/content/aip/proceeding/ aipcp/1652. 